\title{
NEW INDICATION FOR NOVEL BLOCK: SACRAL ERECTOR SPINAE PLANE BLOCK FOR INFERIOR CLUNEAL/SACRAL NERVE ENTRAPMENT SYNDROME
}

$\cdots$ ESRA 2019

\section{S. Tulgar ${ }^{1}$, O. Selvi 1 , D. T. Thomas ${ }^{2}$, Z. Ozer1.}

1-Maltepe University Faculty of Medicine, Anesthesiology and reanimation, Istanbul, Turkey.

2- Maltepe University Faculty of Medicine, Pediatric surgery, Istanbul, Turkey..

ESRA19-0505

\section{Background and Aims:}

-Inferior cluneal nerve entrapment syndrome (ICNES) is a rare and painful condition.

-Piriformis injections, piriformis release and caudal injections are used in the treatment.

- Sacral erector spinae plane block (ESPB) was applied in persistent ICNES

\section{Methods:}

-A 72-year-old female patient, pain in her left inferomedial gluteal region for 4 years.

-Treatment: oral tramadol, gabapentin and paracetamol.

- Formerly, the patient received piriformis injection twice, caudal injection twice in addition to a pudendal nerve block, and a pudendal nerve release surgery.

-High frequency linear transducer was placed on the fifth spinous process on the transverse plane.

- The transducer was then placed 3-4 cm lateral to the second medial sacral crest to visualise the intermediate sacral crest.

- $20 \mathrm{~mL}$ of local anesthetic $(10 \mathrm{~mL}$ bupivacaine $0.5 \%, 5 \mathrm{~mL}$ lidocaine $2 \%, 40$ $\mathrm{mg} / 2 \mathrm{~mL}$ methylprednisolone and $3 \mathrm{~mL}$ normal saline) was injected

\section{Results:}

-The patient expressed relief of her pain after 5 minutes.

-In the third week of postintervention period, she needed no oral medication.

\section{Sacral ESPB may be a good} option in the cases with entrapment syndrome of posterior sacral nerve

\section{branches.}

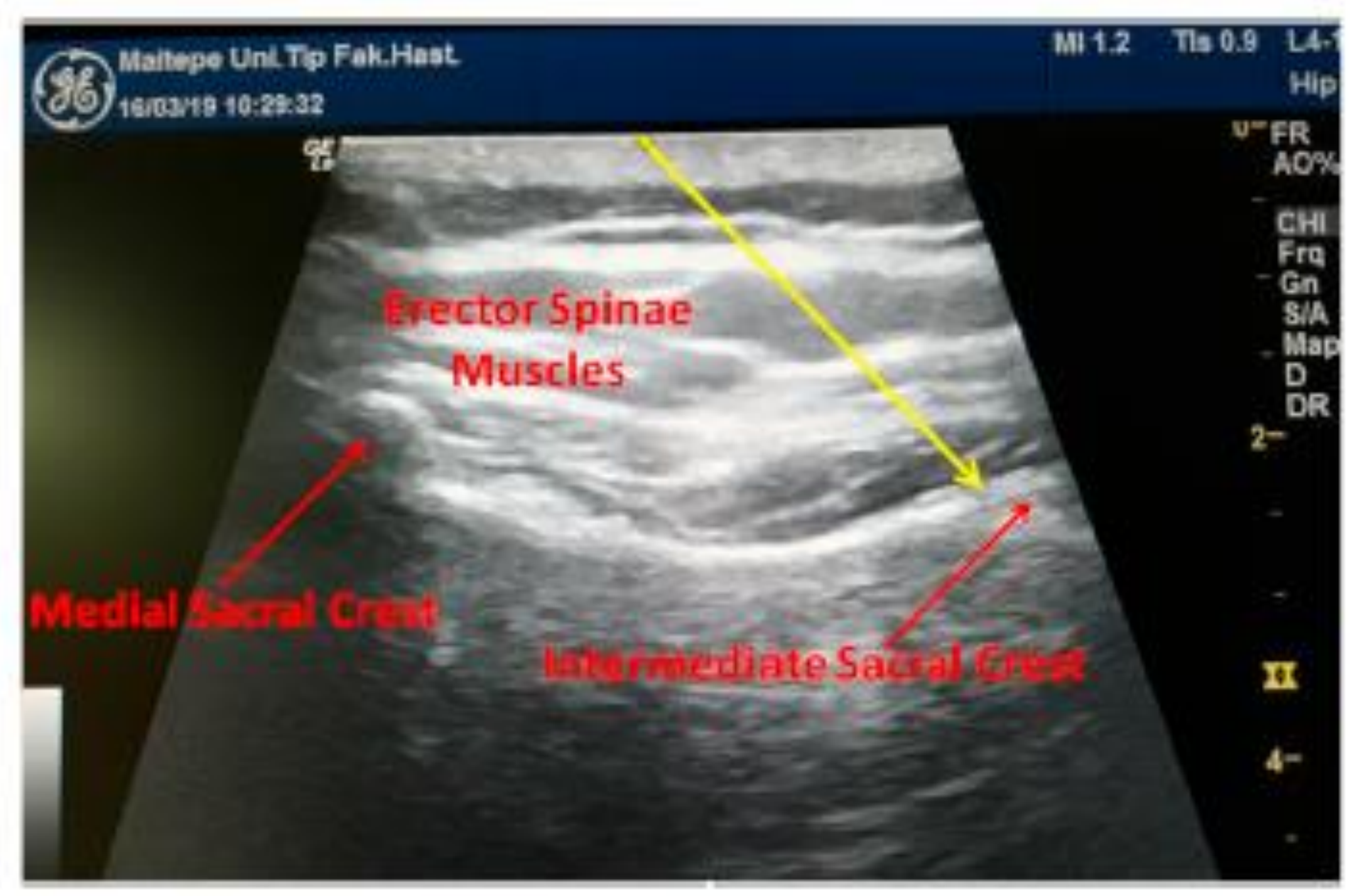

References: 1-A new technique for sensory blockage of posterior branches of sacral nerves: Ultrasound guided sacral erector spinae plane block. Tulgar S, Senturk O, Thomas DT, Deveci U, Ozer Z.

J Clin Anesth. 2019 Nov;57:129-130. doi: 10.1016/j.jclinane.2019.04.014.

2-Ultrasound guided Erector Spinae Plane block at L-4 transverse process level provides effective postoperative analgesia for total hip arthroplasty.

Tulgar S, Senturk O.

J Clin Anesth. 2018 Feb;44:68. doi: 10.1016/j.jclinane.2017.11.006

3-The Maltepe combination: Novel parasacral interfascial plane block and lumbar erector spinae plane block for surgical anesthesia in transfemoral knee amputation.

Tulgar S, Selvi O, Senturk O, Unal OK, Thomas DT, Ozer Z.

J Clin Anesth. 2019 Nov;57:95-96. doi: 10.1016/j.jclinane.2019.03.024

Contact info: Dr. Onur Selvi prostel@yahoo.com Tel: +905337799760 